\title{
LARYNGOLOGY
}

\section{Enhanced recovery program (ERP) in major laryngeal surgery: building a protocol and testing its feasibility}

\author{
Elaborazione e applicazione di un protocollo di enhanced recovery program (ERP) \\ in chirurgia oncologica laringea \\ M. GEMMA', S. TOMA², F. LIRA LUCE², L. BERETTA', M. BRAGA ${ }^{3}$, M. BUSSI $^{2}$ \\ ${ }^{1}$ Head and Neck Department, Anesthesia and Neurosurgical Intensive Care Unit, San Raffaele Hospital, Vita-Salute \\ University, Milan, Italy; ${ }^{2}$ Head and Neck Department, Otorhinolaryngology Unit, San Raffaele Hospital, Vita-Salute \\ University, Milan, Italy; ${ }^{3}$ Department of Surgery, San Raffaele Hospital, Vita-Salute University, Milan, Italy
}

\section{SUMMARY}

Enhanced recovery programs (ERP) represent a multimodal approach to perioperative patient care. The benefits of ERP are well demonstrated in colorectal surgery and Enhanced Recovery After Surgery (ERAS ${ }^{\circledR}$ ) programs, that epitomise the ERP concept, have being introduced in different specialties, including vascular, gastric, pancreatic, urogynecologic and orthopaedic surgery. However, no ERP has been proposed for head and neck surgery. We developed an expert-opinion-based ERP for laryngeal surgery based on the key principles of colorectal surgery ERAS ${ }^{\circledast}$. Twenty-four patients undergoing major laryngeal surgery (total and partial laryngectomies or surgical removal of oropharyngeal tumour with muscle flap reconstruction) were treated according to such an ERP protocol, which differed under several respects from our previous standard practice (described in 70 consecutive patients who underwent major laryngeal surgery before ERP implementation. The adherence rate to the different ERP items is reported. Adherence to ERP items was high. Nutritional assessment, antibiotic prophylaxis, postoperative nausea and vomit (PONV) prophylaxis and postoperative speech therapy targets were applied as required in $100 \%$ of cases. Some ERP items (antibiotic prophylaxis, intraoperative infusion rate, and postoperative speech therapy) were already frequently implemented before ERP adoption. Postoperative medical complications occurred in $8.3 \%$ of patients. Our expert opinion-based ERP protocol for major laryngeal surgery proved feasible. The degree of benefit deriving from its implementation has yet to be assessed.

KEY WORDS: Enhanced Recovery After Surgery • Enhanced Recovery Program • Head and neck surgery $\bullet$ Larynx cancer

\section{RIASSUNTO}

Con il termine Enhanced Recovery Program (ERP) si fa riferimento a protocolli, sempre più utilizzati in ambito chirurgico, che introducono un approccio multimodale evidence-based alla gestione perioperatoria del paziente. In particolare, i benefici derivanti dall'applicazione dei protocolli di Enhanced Recovery After Surgery $\left(E R A S^{\circledR}\right)$ sono stati ampiamente dimostrati nella chirurgia colon-rettale, dove hanno determinato una riduzione della durata della degenza e delle complicanze postoperatorie. Ulteriori protocolli ERP sono stati introdotti in vari campi chirurgici, tra cui la chirurgia vascolare, gastroenterologica, pancreatica, ginecologica, urologica e ortopedica. Nel campo della chirurgia otorinolaringoiatrica, non è ancora stato intrapreso un tentativo di implementazione di un protocollo basato sui principi ERAS®. Lo scopo del nostro lavoro è stato sviluppare un programma ERP per la chirurgia laringea maggiore (laringectomie parziali e totali, rimozione di tumori orofaringei con ricostruzione con lembo nuscolare a cielo aperto), basato sui principi fondamentali del protocollo ERAS ${ }^{\circledast}$ validato nella chirurgia colon-rettale. Ventiquattro pazienti sottoposti a chirurgia oncologica laringea maggiore sono stati trattati con tale protocollo ERP, che differiva sotto molti aspetti dalla nostra precedente pratica standard (descritta sulla scorta di settanta pazienti sottoposti a chirurgia laringea oncologica a cielo aperto prima dell'introduzione del nuovo protocollo). La percentuale di aderenza dei pazienti al protocollo ERP è stata elevata. In particolare gli "items" valutazione nutrizionale preoperatoria, profilassi antibiotica, profilassi PONV (nausea e vomito postoperatori), riabilitazione logopedica post-operatoria, sono stati applicati nel $100 \%$ dei casi. Alcune voci del protocollo ERP (profilassi antibiotica, tassi di infusione intraoperatoria e logopedia postoperatoria) erano state già spesso implementate prima dell'adozione ERP. Si sono presentate poche complicanze postoperatorie di tipo medico (8,3\% dei casi). Il nostro protocollo ERP per la chirurgia laringea maggiore si è rivelato possibile. Il grado di beneficio derivante dalla sua applicazione potrà essere valutato mediante un ulteriore implementazione del campione di studio.

PAROLE CHIAVE: Enhanced Recovery After Surgery • Enhanced Recovery Program • Chirurgia testa collo $\bullet$ Tumore laringeo

Acta Otorhinolaryngol Ital 2017;37:475-478

\section{Introduction}

Different perioperative strategies have been recently developed in an effort to reduce the impact of surgery on hospitalisation. In particular, multimodal approaches to perioperative care, such as Enhanced Recovery
After Surgery $\left(\right.$ ERAS $^{\circledR}$ ) programs, are now frequently implemented in the management of patients undergoing elective surgery. ERAS ${ }^{\circledR}$ protocols include different items, mostly evidence-based, designed to reduce the intra- and perioperative stress response and to support recovery of organ functions, ultimately aiming at help- 
ing patients to recover sooner and with less discomfort after surgery ${ }^{1-4}$.

In the last two decades, the benefits from enhanced recovery programs (ERP) have been well demonstrated in colorectal surgery, where ERAS ${ }^{\circledR}$ is associated with lower morbidity and shorter length of hospital stay ${ }^{5-14}$. New emerging evidence supports the possible advantage that could derive from the implementation of ERPs in other surgical areas. Examples of ERP application can be found in a great number of specialties, such as vascular, gastric, pancreatic, orthopaedic and uro-gynaecological surgery ${ }^{15-23}$. It has recently been suggested that the introduction of ERP could benefit patients undergoing major head and neck surgery ${ }^{24}$.

In the present work, we generated an ERP for major laryngeal surgery and prospectively tested its feasibility in a series of patients.

\section{Materials and methods}

\section{Protocol design}

In a preliminary phase of the study, we developed an ERP for laryngeal surgery. An expert panel (MB, LB, $\mathrm{MG}$ ) reviewed the items and the general principles of the ERAS ${ }^{\circledR}$ colorectal surgery protocols ${ }^{25}$ with the purpose of adapting them to laryngeal surgery. Some items could be directly applied to laryngeal surgery, and were kept unchanged with respect to colon surgery protocols. Other items needed some adaptation due to the relevant differences between colorectal and laryngeal surgery. At the end of this phase we obtained an expert opinion based ERP that could be implemented in the perioperative management of patients undergoing laryngeal surgery.

The 11 items constituting the protocol were:

\section{Psychological counseling}

Preoperative and postoperative meetings with professional psychologists.

\section{Nutritional assessment}

Evaluation of the nutritional status using the MUST (Malnutrition Universal Screening Tool) score system.

\section{Preoperative high carbohydrate drink}

Carbohydrate enteral loading administration on the evening before and 2-3 hours before surgery.

\section{Temperature control}

Intraoperative measurement of patients' temperature and maintenance of normothermia by air blanket and warm intravenous fluid infusions.

\section{Antibiotic prophylaxis}

Administration of iv cefoxitin ( $2 \mathrm{~g}$ if body weight $>50 \mathrm{~kg}$; $1 \mathrm{~g}$ if body weight $<50 \mathrm{~kg})$ and clindamycin $(600 \mathrm{mg})$ 0-30 minutes before surgery, to be repeated every 3 hours for cefoxitin and every 6 hours for clindamycin.

6. Postoperative nausea and vomiting (PONV) prophylaxis Intraoperative administration of iv ondansetron $(4 \mathrm{mg})$ and dexamethasone (4 mg) 2 hours before the end of surgery.

\section{Intraoperative iv infusions}

Targeting $6 \mathrm{ml} / \mathrm{kg} / \mathrm{h}$ mean intraoperative fluids infusion by the end of surgery.

\section{Postoperative pain control}

Administration of iv paracetamol ( $1 \mathrm{~g}$ every 6 hours $)$ and morphine by Patient Controlled Infusion (PCA - $1 \mathrm{mg} / 10$ $\min , \max 4 \mathrm{mg} / \mathrm{h}$ ).

\section{Early enteral nutrition}

Start of enteral nutrition on the first postoperative day.

\section{Early mobilisation}

Start of patient mobilisation (sitting position and ambulation) on the first postoperative day.

\section{Postoperative speech therapy}

Postoperative meetings with speech therapists, including speech and breathing exercises.

\section{Protocol evaluation}

In a second phase of the study consecutive patients undergoing elective major laryngeal surgery (total and partial laryngectomies or surgical removal of oropharyngeal tumour with muscle flap reconstruction) between October 2011 and May 2014 in our hospital were considered. Exclusion criteria were: refusal to sign the informed consent form, pregnancy and age less than 18 years. Moreover, patients living outside the area of Milan, where our hospital is located, were not considered, since in this phase preoperative and postoperative protocol items could be difficult to implement.

Patient adherence to each protocol item was recorded in a dedicated database as a no/yes variable, except for the intraoperative iv infusions that were recorded as $\mathrm{ml} / \mathrm{kg} / \mathrm{h}$. We also recorded the postoperative day (POD) of first liquid oral assumption, first solid food oral assumption, nasogastric tube removal, hospital discharge, daily hours of mobilization during postoperative day 1-4, postoperative need for vasopressor and transfusion and occurrence of medical complications. Medical complications were meant to include respiratory complications, cardiovascular events and urinary tract complications.

In order to sketch the differences between our ERP and our routine pre-ERP practice, we retrieved data from the 75 consecutive patients who underwent major laryngeal surgery before the ERP protocol implementation, from October 2008 to September 2011. For these cases, we could retrieve data about all of the 11 ERP items, nasogastric tube removal, hospital discharge, postoperative vasopressor and transfusion need and medical complications. Pre-ERP data are reported exclusively for documentary purposes in order to show that the ERP protocol represented a change from our previous practice. No formal comparison is attempted between pre-ERP and ERP data. Continuous data are reported as mean \pm SD. Discrete variables were reported as number-percentage (95\% CI). The statistical software Stata 11.1 (StataCorp, College Station, Texas, USA) was used to analyse data. 


\section{Results}

During the study period 76 patients underwent elective major laryngeal surgery in our Hospital. Thirty-nine (51\%) lived outside the area of Milan, 10 (13\%) refused to sign the informed consent form and 3 (4\%) were less than 18 years old, so that $24(32 \%)$ patients were enrolled.

Table I reports on the implementation of our 11 ERP items. Adherence to ERP items was high. Nutritional assessment, antibiotic prophylaxis, PONV prophylaxis and postoperative speech therapy targets were applied as required in $100 \%$ of cases. Early mobilisation was the item with the lowest adherence to protocol target (70.8\% (51.290.4) of cases).

In ERP patients, oral intake of fluids started on POD $11 \pm 5.7$ and oral intake of solid food on POD $12 \pm 5.3$. These patients were mobilised $1.8 \pm 2.1$ hours on POD 1, $3.8 \pm 2.9$ hours on POD 2, $5.8 \pm 3.2$ hours on POD 3 and $6.2 \pm 3.1$ hours on POD 4 .

Postoperative nasogastric tube removal occurred on the $16 \pm 5$ POD. Vasopressors were needed in $8.3 \%$ of ERP patients and postoperative transfusions were necessary in $12.5 \%$ of cases. Hospital discharge occurred on the $21 \pm 8$ postoperative day.

Postoperative medical complications occurred in $8.3 \%$ of cases. The majority of our ERP items were infrequently or never implemented before the adoption of the ERP protocol, except antibiotic prophylaxis, intraoperative infusion rate and postoperative speech therapy, which were already implemented in a high percentage of cases before the adoption of the ERP protocol.

\section{Discussion}

ERP principles, epitomised in ERAS ${ }^{\circledR}$ protocols, are increasingly adopted in many surgical settings, but no ERP has been yet proposed in otolaryngology, although its usefulness has been strongly suggested ${ }^{24}$.

It is conceivable that the favourable results of ERP implementation in several surgical settings ${ }^{5-23}$ fostered a positive attitude towards ERP principles in physicians and nurses involved in the perioperative care of major surgery patients. This possibly accounts for the high adherence to protocol items that we easily obtained in our series. Some items were even satisfied in $100 \%$ of cases (namely nutritional assessment, antibiotic prophylaxis, PONV prophylaxis and postoperative speech therapy), exhibiting the highest degree of feasibility. As an example, it is noteworthy that some items were already implemented in our pre- ERP patients, plainly reflecting good common clinical practice. This holds true for both antibiotic prophylaxis and postoperative speech therapy.

The mean intraoperative infusion rate in ERP patients was only slightly lower than in pre-ERP patients and approached the $6 \mathrm{ml} / \mathrm{kg} / \mathrm{h}$ target without meeting it. We
Table I. ERP items implementation.

\begin{tabular}{|c|c|c|c|}
\hline ERP protocol & & ERP & Pre-ERP \\
\hline Item & Target & $(n=24)$ & $(n=75)$ \\
\hline $\begin{array}{l}\text { 1. Psychological } \\
\text { counseling * }\end{array}$ & $100 \%$ & $\begin{array}{c}23 \\
95.8 \%(87.2-1.0)\end{array}$ & $\begin{array}{c}31 \\
41.3 \%(29.9-52.7)\end{array}$ \\
\hline $\begin{array}{l}\text { 2. Nutritional } \\
\text { assessment * }\end{array}$ & $100 \%$ & $\begin{array}{c}24 \\
100 \%\end{array}$ & $\begin{array}{c}0 \\
0 \%(0-0)\end{array}$ \\
\hline $\begin{array}{l}\text { 3. Preoperative } \\
\text { glucose drink * }\end{array}$ & $100 \%$ & $\begin{array}{c}20 \\
83.3 \%(67.3-99.4)\end{array}$ & $\begin{array}{c}0 \\
0 \%(0-0)\end{array}$ \\
\hline $\begin{array}{l}\text { 4. Temperature } \\
\text { control * }\end{array}$ & $100 \%$ & $\begin{array}{c}23 \\
95.8 \%(87.2-100)\end{array}$ & $\begin{array}{c}47 \\
62.7 \%(51.5-73.9)\end{array}$ \\
\hline $\begin{array}{l}\text { 5. Antibiotic } \\
\text { prophylaxis * }\end{array}$ & $100 \%$ & $\begin{array}{c}24 \\
100 \%\end{array}$ & $\begin{array}{c}73 \\
97.3 \%(93.6-100)\end{array}$ \\
\hline $\begin{array}{l}\text { 6. PONV } \\
\text { prophylaxis * }\end{array}$ & $100 \%$ & $\begin{array}{c}24 \\
100 \%\end{array}$ & $\begin{array}{c}41 \\
54.7 \%(43.1-66.2)\end{array}$ \\
\hline $\begin{array}{l}\text { 7. Intraoperative iv } \\
\text { infusions }(\mathrm{ml} / \mathrm{kg} / \mathrm{h}) \S\end{array}$ & 6 & $7.2 \pm 3.0$ & $7.8 \pm 3.1$ \\
\hline $\begin{array}{l}\text { 8. PO Morphine } \\
\text { PCA * }\end{array}$ & $100 \%$ & $\begin{array}{c}23 \\
95.8 \%(87.2-100)\end{array}$ & $\begin{array}{c}48 \\
65.3 \%(52.9-75.2)\end{array}$ \\
\hline $\begin{array}{l}\text { 9. Early enteral } \\
\text { nutrition * }\end{array}$ & $100 \%$ & $\begin{array}{c}19 \\
79.2 \%(61.7-96.7)\end{array}$ & $\begin{array}{c}68 \\
90.7 \%(82.1-98.7)\end{array}$ \\
\hline 10. Early mobilisation & $100 \%$ & $\begin{array}{c}17 \\
70.8 \%(51.2-90.4)\end{array}$ & $\begin{array}{c}26 \\
34.7 \%(23.6-45.7)\end{array}$ \\
\hline $\begin{array}{l}\text { 11. Postoperative } \\
\text { logopaedia * }\end{array}$ & $100 \%$ & $\begin{array}{c}24 \\
100 \%\end{array}$ & $\begin{array}{c}68 \\
90.7 \%(82.1-98.7)\end{array}$ \\
\hline
\end{tabular}

believe that this reflects a tendency to administer less intraoperative fluids independently from ERP protocols, but this certainly also points at some difficulty in coping with intraoperative fluid restriction by anaesthesiologists.

Our study did not address the issue of ERP outcomes and was not adequately powered for this.

Moreover, the best choice of consistent ERP outcome variables in laryngeal surgery may be challenging. We reported the timing of postoperative nasogastric tube removal and hospital discharge in our series. With respect to these issues, although the reduction of both postoperative fasting and hospital length of stay is a cornerstone of ERAS $^{\circledast}$ programs, the optimal timing for nasogastric tube removal after major laryngeal surgery is clearly dictated by anatomical reasons and its evaluation as a possible ERP outcome is questionable. Similar considerations may be appropriate for hospital discharge, as surgical postoperative evaluation may require specific timing.

A further limitation of our study is that we did not register the POD in which patients were "fit to discharge", but rather the actual discharge POD, which is subject to bias due to administrative and organisational variables.

In building our ERP protocol we adapted a series of ERP items to the laryngeal surgery setting. This process was expert-opinion based and entails some degree of subjectivity. Although other approaches could yield different 
ERP protocols, our 11 items seem to adequately epitomise ERP philosophy.

\section{Conclusions}

Our expert-opinion-based ERP protocol for major laryngeal surgery proved feasible. The degree of benefit deriving from its implementation has yet to be assessed.

\section{References}

1 Calder PC. Immunonutrition. BMJ 2003;327:117-8.

2 Stableforth WD, Thomas S, Lewi SJ. A systematic review of the role of immunonutrition in patients undergoing surgery for head and neck cancer. Int J Oral Maxillofac Surg 2009;38:103-10.

3 Moskovitz DN, Kim YI. Does perioperative immunonutrition reduce postoperative complications in patients with gastrointestinal cancer undergoing operations? Nutr Rev 2004;62:443-7.

4 Bianchini C, Ciorba A, Stomeo F, et al. Immunonutrition in head and neck cancer: have a look before surgery! Eur Arch Otorhinolaryngol 2012;269:5-8.

5 Melnyk M, Casey RG, Black P, et al. Enhanced recovery after surgery (ERAS) protocols: time to change practice? Can Urol Assoc J 2011;5:342-8.

6 Wind J, Polle SW, Fung Kon Jin, et al. Systematic review of enhanced recovery programmes in colonic surgery. Br J Surg 2006;93:800-9.

7 Kehlet H, Mogensen T. Hospital stay of 2 days after open sigmoidectomy with a multimodal rehabilitation programme. Br J Surg 1999;86:227-30.

8 Eskicioglu C, Forbes SS, Aarts MA, et al. Enhanced recovery after surgery (ERAS) programs for patients having colorectal surgery: a meta-analysis of randomized trials. $\mathbf{J}$ Gastrointest Surg 2009;13:2321-9.

9 Lassen K, Soop M, Nygren J, et al. Consensus review of optimal perioperative care in colorectal surgery: Enhanced Recovery After Surgery (ERAS) Group recommendations. Arch Surg 2009;144:961-9.

10 Abraham N, Albayati S. Enhanced recovery after surgery programs hasten recovery after colorectal resections. World J Gastrointest Surg 2011;3:1-6.

11 Sammour T, Zargar-Shoshtari K, Bhatet A, et al. A programme of Enhanced Recovery After Surgery (ERAS) is a cost-effective intervention in elective colonic surgery. $\mathrm{N} \mathrm{Z}$ Med J 2010;123:61-70.

12 Teeuwen PH, Bleichrodt RP, de Jong PJ, et al. Enhanced recovery after surgery versus conventional perioperative care in rectal surgery. Dis Colon Rectum 2011;54:833-9.
13 Varadhan KK, Neal KR, Dejong CHC, et al. The enhanced recovery after surgery (ERAS) pathway for patients undergoing major elective open colorectal surgery: a meta-analysis of randomized controlled trials. Clin Nutr 2010;29:434-40.

14 Srinivasa S, Sammour T, Kahokehret A, et al. Enhanced Recovery After Surgery (ERAS) protocols must be considered when determining optimal perioperative care in colorectal surgery. Ann Surg 2010;252:409.

15 Sjetne IS, Krogstad U, Ødegård S, et al. Improving quality by introducing enhanced recovery after surgery in a gynaecological department: consequences for ward nursing practice. Qual Saf Health Care 2009;18:236-40.

16 Minig L, Biffi R, Zanagnolo V, et al. Early oral versus "traditional" postoperative feeding in gynecologic oncology patients undergoing intestinal resection: a randomized controlled trial. Ann Surg Oncol 2009;16:1660-8.

17 Pruthi RS, Chun J, Richman M. Reducing time to oral diet and hospital discharge in patients undergoing radical cystectomy using a perioperative care plan. Urology 2003;62:661-5.

18 Lee J, Jeon H. The Clinical indication and feasibility of the enhanced recovery protocol for curative gastric cancer surgery: analysis of 147 consecutive experiences. Dig Surg 2014;31:318-323.

19 Braga M, Pecorelli N, Ariotti R, et al. Enhanced recovery after surgery pathway in patients undergoing pancreaticoduodenectomy. World J Surg 2014;38:2960-6.

20 Savaridas T, Serrano-Pedraza I, Khan SK, et al. Reduced medium-term mortality following primary total hip and knee arthroplasty with an enhanced recovery program. A study of 4,500 consecutive procedures. Acta Orthop 2013;84:40-3.

21 Melnyk M, Casey RG, Black P, et al. Enhanced recovery after surgery (ERAS) protocols: time to change practice? Can Urol Assoc J 2011;5:342-8.

22 Podore PC, Throop EB. Infrarenal aortic surgery with a 3-day hospital stay: a report on success with a clinical pathway. J Vasc Surg 1999;29:787-92.

${ }^{23}$ Feo CV, Romanini B, Sortini D, et al. Early oral feeding after colorectal resection: a randomized controlled study. ANZ J Surg 2004;74:298-301.

24 Bianchini C, Pelucchi S, Pastore A, et al. Enhanced recovery after surgery (ERAS) strategies: possible advantages also for head and neck surgery patients? Eur Arch Otorhinolaryngol 2014;271:439-43.

25 Gustafsson UO, Scott MJ, Schwenket W, et al. Guidelines for perioperative care in elective colonic surgery: Enhanced Recovery After Surgery $\left(E R A S^{\circledR}\right)$ Society recommendations. World J Surg 2013;37:259-84. 